\title{
INCLUSÃO DIGITAL NA ADULTEZ TARDIA E O REENCANTAMENTO DA APRENDIZAGEM
}

Denise Goulart

Anderson Jackle Ferreira²

Juan José Mouriño Mosquera ${ }^{3}$

Claus Dieter Stobäus ${ }^{4}$

resumo

O artigo traz um breve histórico da sociedade, das Tecnologias de Informação e Comunicação, a etapa da vida denominada adultez tardia e a aprendizagem ao longo da vida. São várias as motivações na vida dos adultos tardios que procuram cursos para aprenderem informática como: o desejo de aprender mais ou continuar aprendendo para não serem excluídos, tanto da sociedade como do seu núcleo familiar, por não falarem e entenderem a linguagem no uso de tecnologias; superar as dificuldades e dominar o uso do compu-

1 Doutora em Gerontologia Biomédica pela Pontifícia Universidade Católica do Rio Grande do Sul (PUCRS). Mestre em Educação pela Pontifícia Universidade Católica do Rio Grande do Sul (PUCRS). E-mail: denisegoulart2010@hotmail.com

2 Doutor em Gerontologia Biomédica pela Pontifícia Universidade Católica do Rio Grande do Sul (PUCRS). Mestre em Gerontologia Biomédica pela (PUCRS). E-mail: anderson@jackle.com.br

3 Pós-doutor em Psicologia pela Universidad Autónoma de Madrid. Livre Docente em Psicologia da Educação. Professor Titular, Faculdade de Educação e de Letras da Pontifícia Universidade Católica do Rio Grande do Sul (PUCRS). E-mail: mosquera@pucrs.br

4 Pós-doutor em Psicologia pela Universidad Autónoma de Madrid. Doutor em Ciências Humanas - Educação. Professor Titular, Programa de Pós-Graduação em Educação, Programa de Pós-Graduação em Gerontologia Biomédica, Professor do Centro Universitário La Salle. E-mail: stobaus@pucrs.br 
tador; melhorar a relação intergeracional; e realizar-se pessoalmente, aumentando sua autoestima.

palavras-chave

Adultez Tardia. Inclusão Digital. Tecnologias de Informação e Comunicação. Aprendizagem.

\section{Introdução}

O conhecimento sempre foi um diferencial e determinante para evolução e termos de história da humanidade, pois quem o domina, consequentemente 'domina outros povos', ainda hoje. Todos os avanços evolutivos dos seres humanos alicerçaram-se no conhecimento, não somente no sentido de dominação, mas também na sua inter-relação com o sentido de conseguir sua humanização e sua humanidade.

Araújo (1994, p. 84) afirma que o poder transformador de deter a informação gera mudanças em toda uma sociedade, ainda mais com a Tecnologia que temos hoje:

\section{[...], pois se a informação é a mais poderosa força de transformação do homem, o poder da informação, aliado aos modernos meios de comunicação de massa, tem capacidade ilimitada de transformar culturalmente o homem, a sociedade e a própria humanidade como um todo.}

As mudanças da sociedade ocorrem, geralmente, na forma de ruptura de paradigmas, referentes sempre a um modelo e padrões compartilhados em determinado espaço-tempo, que permitem a explicação de certos aspectos da realidade. Com isso, entendemos que surge uma forma de pensamento algumas vezes totalmente diferente, sendo uma transição de um modelo para outro, explicando o que o anterior já não explicava, ou sustentava mais. Paradigma é mais do que uma teoria, pois implica uma estrutura que gera novas teorias, é algo que estaria no início das teorias, “[...] um paradigma pode ao mesmo tempo elucidar e cegar, revelar e ocultar e os indivíduos conhecem, pensam e agem segundo paradigmas inscritos culturalmente neles", destacava Morin (2001, p. 25). 
Osório (2003, p. 33) explica que entramos "[...] num novo paradigma tecnológico, centrado na engenharia genética e nas tecnologias da informação, e nas comunicações baseadas na microeletrônica".

Assim, com tantas mudanças, houve uma transição da sociedade de produção artesanal para uma sociedade de produção em massa, até chegar à sociedade do conhecimento, sociedade da informação, sociedade aprendente, colocada por Assmann (1998), em que tudo está conectado em redes digitais e tecnologias cada vez mais eficientes, para a construção de novos conhecimentos e ferramentas, não significando que somente o acesso aos dados e às informações que estão disponibilizados na Internet seja o diferencial para que aconteça a aprendizagem, mas que o significado que eles representam transformam-os no próprio conhecimento.

Para Morin (2001, p. 86), “[...] o conhecimento é a navegação em um oceano de incertezas, entre arquipélagos de certezas" e é a principal matériaprima dessa nossa atual sociedade, juntamente com as informações que rapidamente (porém superficialmente) recebemos diariamente, por isso temos de saber processar e separar o excesso de informações (ditas inúteis), a fim de que o conhecimento torne-se mais organizado e possa ser rapidamente (re)construído, pois ele tem um papel determinante para que ocorram novas e boas aprendizagens, que sejam mais significativas, transformando a ação do sujeito no mundo e atuando na própria mudança deste mesmo mundo, humanamente construído. Para isso acontecer, antes ele deve estar acessível, de modo democratizado.

Mosquera (2003, p. 52) corrobora com estas idéias, quando afirma que:

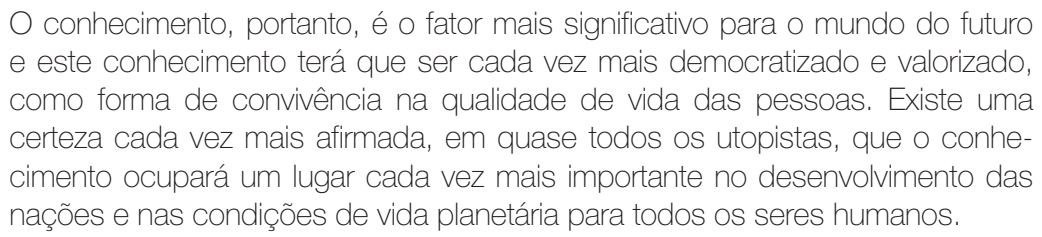

Como afirma Osório (2003, p. 35), “[...] embora a sociedade sempre tenha estado em mutação, a mudança social é hoje muito mais acelerada". Com o advento de cada vez mais tecnologias, ocorre uma verdadeira revolução no cotidiano das pessoas, que vêm impulsionando-as para uma sociedade emergente e, sobretudo, cada vez mais conectada e interativa, ao mesmo tempo em que esse mesmo ser humano vem se tornando cada vez mais dependente das Tecnologias de Informação e Comunicação. 
Vanzo (2000, p. 20) comenta que o grande responsável por essa nova revolução:

[... é é desenvolvimento do conhecimento humano, que cresce numa velocidade alucinante, dobrando a cada três anos e, segundo estudos divulgados pela consultoria Arthur Andersen, em 2020 dobrará a cada 73 dias [...], uma vez integrada em nossas vidas, estas descobertas e tecnologias nos permitirão experimentar novas possibilidades que no seu ápice irão gerar novas demandas para novas descobertas.

Na sociedade aprendente, quando utilizamos os recursos destas TICs, podemos aprender rápida e continuamente, de forma flexível, através de um planejamento e execussão bem elaborados, sem rigidez excessiva, aproximando mais as pessoas, pelas conexões on-line, em tempo real e permitindo que, mesmo na Educação formal, as pessoas interajam e possam formar pequenas comunidades de aprendizagem, fazendo com que o aprendiz transforme-se no protagonista da sua própria formação.

Borges (2000, p. 32) enfatiza que, “[...] através das Tecnologias de Informação e Comunicação, o mundo transformou-se em uma sociedade globalizada e globalizante, com novos mercados, novas mídias e novos consumidores", e comenta que:

[... o o homem, diante dessa nova realidade, continua o mesmo: íntegro na sua individualidade, na sua personalidade, nas suas aspirações, na defesa de seus direitos, na busca da sua felicidade e de suas realizações, e no comando desta mudança, como o único ser dotado de vontade, inteligência e conhecimento capaz de compreender os desafios e definir os passos que direcionarão seu próprio futuro. (2000, p. 32)

Portanto, inserir-se e poder participar na sociedade de informação tornou-se mais que uma necessidade, agora é quase que uma obrigatoriedade, tanto para os países considerados desenvolvidos e os em vias de desenvolvimento, como para as próprias pessoas, sem o que somos já considerados 'desplugados, out, ultrapassados'.

Mosquera (2003, p. 52) chama atenção de que o "conhecimento atomizado, memorístico e enciclopédico" está com seus dias contados, e salienta que:

O mais importante parece ser o conhecimento em totalidade atendendo os diferentes tipos de inteligências e saberes, acreditando que o potencial humano de conhecimento é extraordinário e que todas as pessoas têm o poder de ampliar a sua maneira de perceber e sentir o mundo que as rodeia [...] com a possibilidade de compreender a totalidade e o inacabamento do conhecimento e despertando, cada vez mais, a curiosidade, a imaginação e a fantasia. 
Como bem destaca Ferreira (2008), a inclusão digital está transformandose rapidamente em uma parte indissociável de algo maior, a própria inclusão social. Diante disso, um novo e grande desafio é apresentado para a área da Educação, que está tendo que investir muito esforço para que a sociedade, como um todo, passe a conseguir atuar de forma mais harmônica, com o uso destas novas e variadas TICs, lembrado também por Mosquera, Ferreira e Stobäus (2009), as quais têm a vantagem de uma cada vez maior individualização da aprendizagem, possibilitando que cada pessoa seja a protagonista de sua própria construção de conhecimento, no momento e no local em que possa realizá-lo, e aprenda em seu próprio ritmo, em uma contínua transformação, tanto de si como da sociedade em que vive e atua.

\section{Adulto Tardio e a Aprendizagem ao Longo da Vida}

Desde que nascemos, buscamos compreender o mundo a partir de nossas entradas sensoriais e transformações cerebrais que constantemente (re)fazemos, em determinados ambientes, que deveriam ser todos propícios, com clara conotação de valores e crenças da cultura à qual pertencemos. Nesse infinito processo de construção e reconstrução rápida de nosso conhecimento, deparamo-nos com objetos, cores, formas, pessoas, ambientes, situações, enfim, dados novos que a todo o momento nos impulsionam as descobertas, e (re)fazemos estruturas de pensamento e construção de novos saberes, desde crianças mas não somentre naquela fase, pois estamos sempre nos desenvolvendo, até morrer, dizem Stobäus e Mosquera (2010).

Dessa forma, somos capazes de ampliar nossos conhecimentos, habilidades e atitudes, construindo-os através das diversas possibilidades de interação com o nosso meio, bem destacado por Vygotsky (1993).

Claxton (2005, p. 20) afirma que a aprendizagem modifica nosso conhecimento, agir e mesmo o nosso modo de ser. Somos sujeitos ativos nesse processo, analisando, realizando tentativas, testando hipóteses embasados em (nossas) informações, agindo sobre eles e novamente aprendendo a aprender, constantemente. Isso significa que não apenas acumulamos informações, mas que também atribuímos algum significado a elas, de acordo com nossas capacidades de compreensão e conhecimentos prévios, fazendo contínuo processo de aprendizado, que ocorre ao longo de toda nossa vida, e: 

necessários para buscar atingi-los e suas atuais potencialidades e fragilidades nesse aspecto.

Entretanto, alguns teóricos têm postulado a ideia do conhecimento que poderia desenvolver-se em rede, que podemos entender como uma metáfora, significando uma teia na qual tudo está interligado. Nessa interconexação, os fenômenos são observados e descritos por conceitos, modelos e teorias. Não há nada indispensável ou fundamental, que esteja em primeiro ou segundo plano, pois as bases do conhecimento não são mais fixas e imutáveis. O entendimento do conhecimento em rede colabora para a visão de transformação rápida e constante (do potencial) do próprio conhecimento. As teias que se ampliam em um processo de interação de saberes geram uma estrutura sempre maior e mais qualificada de compreensão, refutando mesmo a forma desarticulada e fragmentada atual. Nessa nova interação, a pessoa participaria da (re)construção de seu conhecimento, não apenas com o uso predominante do raciocínio e da percepção e entendimento do mundo exterior pelos sentidos, mas também usando suas sensações, sentimentos e emoções, bem como sua intuição para aprender mais e aprofundadamente.

Osório (2003, p. 32) afirma que:

[... o conhecimento vai ser o principal recurso produtor de riqueza, o que supõe que os membros da sociedade não só devem ter uma formação básica, mas também incorporar conhecimentos de informática, de tecnologia, aspectos que não eram imprescindíveis até a uma década. Por isso, a educação contínua e permanente será uma atividade florescente, apesar de a escola e a universidade a olharem, na sua opinião, com certa desconfiança.

A Educação, então, deveria perpassar uma real e efetiva educação social, na qual pudéssemos implementar processos, ao longo de toda nossa vida, e possibilitar melhores condições e mais adequadas aprendizagens significativas, não sendo uma simples transmissão de conhecimento, mas superando o que já existe, e possibilitando, assim, maior autonomia para as pessoas com sessenta ou mais anos, a fim de terem condições de viver um futuro melhor.

Mosquera (1993, p. 128) comentava que:

Importante seria colocar a pessoa idosa ante as mudanças rápidas dos conhecimentos e costumes, ao mesmo tempo incentivá-la de que não é ignorante, nem tola. Cremos que são pessoas que podem adquirir algo que se chama educação informal, estando a par do que se passa pelo mundo, pois são também parte deste mundo. 
Hoje, ele utiliza a nomenclatura adulto tardio, no sentido de que a adultez inicia ao final de um ciclo denominado de adolescência, por volta dos 20 anos (que em alguns casos vai até bem adiante), e que culmina, no mundo mais ocidental e pragmático, com a morte biológica. $\mathrm{O}$ autor destaca que esse adulto tardio sempre está a aprender, até um ponto que denomina de sabedoria.

Portanto, para Papalia e Olds (2000, p. 511), “[...] as pessoas mais velhas podem e efetivamente continuam a adquirir novas informações e habilidades e são capazes de lembrar e usar aquelas que já conhecem".

Para Claxton (2005, p. 24), o aprender ao longo da vida deve:

[... significar mais do que adultos indo para a escola a fim de aprender a usar a Internet [...]; significa ter a capacidade de lidar de modo inteligente com a incerteza e a persistir diante da dificuldade [...] significa fazer escolhas sobre quais convites de aprendizagem aceitar e quais declinar.

Segundo ele (p. 238), “[...] durante a idade adulta, podem ser desenvolvidas tanto a reflexão e a autopercepção, como também a aptidão para assumir uma visão geral, estratégica e responsável do próprio caminho da aprendizagem".

As TICs auxiliam, sem dúvida, a alavancar cada vez mais estas rápidas mudanças em todas as sociedades em que estão presentes, provocando inúmeras e velozes transformações em todas estas esferas sociais, apontando novas tendências de valores e concepções de vida. Por consequência, nossa sociedade e, principalmente, os seus adultos tardios, precisam atender estas 'novas necessidades', ao tentarem adaptar-se às imprevisíveis demandas geradas pelas mudanças, pois essas acontecem de uma forma veloz e desigual, contribuindo para que apareçam grandes diferenças em diferentes países. Isso implica em que co-existam essas verdadeiras ‘barreiras' bem perto de nós mesmos, que é a denominada exclusão digital, com o analfabetismo digital funcional, à semelhança do analfabetismo funcional (daqueles que não tiveram acesso à Educação).

Mas essas mesmas TICs abrem novas possibilidades e trazem novas exigências para desenhar a aprendizagem e o viver no século XXI. Diante de tal cenário, nos questionamos: de que forma a Educação poderia ser repensada para incluir em sua estrutura a conscientização de uma prática que estabeleça as bases para uma educação continuada, que atinja pessoas que estão com mais de sessenta anos? Como articular condições favorecedoras de aprendizado entre os adultos tardios, frente aos desafios de um mundo pautado em tecnologias que evoluem tão rapidamente? 
A partir dessas reflexões sobre processos constantes de mudança social, registrados nos últimos anos, devemos pensar em um debate mais aprofundado sobre elas, que estão a afetar tanto a esfera pessoal, como a profissional, e mesmo a social. Talvez, o desafio mais importante do século XXI esteja em conseguir preparar as novas gerações, integrando os adultos tardios nesses novos contextos, através de uma aprendizagem de, e com, novas tecnologias, para avançar em aprendizagens digitais.

\section{Inclusão Digital do Adulto Tardio}

Com o crescente aumento da população idosa mundial, inclusive no Brasil, devemos começar a ter novos olhares para com esses adultos tardios e a pensar como melhor podem viver nessa fase da vida, mesmo diante de tantos limites que o envelhecimento lhes proporciona. Isso não significa, porém, que eles tenham que se abster de tudo o já adquirido, mas devem continuar a aprender, trabalhar, ter vida social ativa e desfrutar de hobbies e momentos de ócio e lazer, claro que auxiliados pelas TICs. A ideia proposta (e muitas vezes imposta) pela sociedade contemporânea, de que após determinada idade (por exemplo, sessenta ou mais) algumas atividades não devem mais ser 'desfrutadas', é uma concepção que vem sendo superada devido às constantes transformações sociais, uma medicina moderna, crescente longevidade, uso de tecnologias aplicadas ao campo do trabalho, ócio e lazer. Já que a própria expectativa de vida vem aumentando muito, surge a necessidade de repensar como envolver essas pessoas em aprendizagens constantes em seus tempos livres, após a sua aposentadoria ou dimunuição gradativa de atividades mais 'pesadas e difíceis'.

Stobäus e Giraffa (1994) salientavam que:

Os adultos, quando se iniciam na operação de computadores, posteriormente na programação ou utilização de algum software pronto, são especialistas em alguma área e não dominam bem estes equipamentos. Quando se vêem diante de uma máquina desconhecida, fora do seu conhecimento, eles se ressentem de sair de uma posição de domínio para uma posição de iniciante, e isto pode comprometer significativamente o processo de aprendizagem (lembremonos de motivação, expectativas, interesses, medo de errar,...). [...]. O uso do computador nas atividades pedagógicas produz ainda uma peculiar situação, pois quando o aluno busca a solução de um problema também se torna professor, uma vez que ele ensina o computador a fazer coisas (isto é, aprende a como fazê-lo na própria interação com ele). 
Muito consoante a esses elementos, cabe destacar aqui o estudo de Goulart (2011), que investigou adultos tardios em inserção digital, que ainda não haviam utilizado essas ferramentas, aprendendo o uso do computador e as ferramentas, como Word, Internet, de modo que pudessem aprender sem erro, com a monitorização de suas atividades, que foram supervisonadas pela autora e monitores.

O estudo, de caráter exploratório-descritivo, foi desenvolvido na abordagem de um Estudo de Caso, adotando uma metodologia quanti-qualitativa, com a Intervenção de cunho longitudinal. Teve como objetivo geral analisar o efeito de uma metodologia de aprendizagem sem erro em Oficinas de Inclusão Digital para adultos tardios, buscando, assim, argumentos para a confirmação da Tese de que a técnica de aprendizado sem erro auxilia no ensino de Informática em Oficinas de Inclusão Digital.

A amostra foi constituída por vinte e cinco pessoas, divididas em dois grupos (14/11), nomeados por Grupo 1 e 2, apresentando média de idade de sessenta e oito anos, sendo que onze possuíam curso universitário completo. Em relação à Informática, foi destacado que treze do Grupo 1 e onze do Grupo 2 possuíam computador. Durante o desenvolvimento das atividades de Intervenção intencional, os dados foram coletados através de observação participante, acompanhando e pontuando os progressos e as dificuldades de cada um deles, em cada encontro, em uma Ficha de Avaliação de Rendimento. Cada operação desenvolvida foi solicitada pelo mesmo número de vezes e, dessa forma, foi possível observar quais atividades de ensino em Informática foram as que tiveram maior êxito e/ou dificuldade.

Os dados quantitativos da Ficha Informativa com os dados sócio-demográficos do Grupo 1 e 2 receberam tratamento de Estatística Descritiva, os Testes com análise de Estatística Inferencial (ANOVA seguida do teste post hoc de Tukey, quando necessário, e os dados categóricos com teste Qui-quadrado). Os efeitos (número de erros nas situações de teste) da abordagem metodológica das Oficinas de Inclusão Digital sobre o aprendizado dos idosos foram analisados pelo teste T de Student para amostras independentes. O efeito das Oficinas de Inclusão Digital nos aspectos cognitivos dos idosos que participaram delas com Teste $t$ de Student para amostras (IN) dependentes.

Todos os resultados foram expressos com média \pm erro padrão, $\mathrm{p}<0,05$, sendo detectado que houve uma diferença significativa, isto é, o método mostrou-se eficaz. Complementarmente, os dados qualitativos foram categorizados pela Análise de Conteúdo de Bardin: apreciar o método; sentir-se incluídos, aprender sem temor; seri mais prazeroso trabalhar sem erro, e ficar 
sem receio de errar; melhorar em sua autoestima; experienciar sentimentos de alegria; partilhar com colegas.

Com esses resultados, voltamos a ressaltar que todos os adultos tardios deveriam ter o direito ao acesso e ao uso das TICs, não sendo limitados por questões sociais, geográficas e financeiras e que devemos combater todos os elementos que fazem com que inexista inclusão digital.

Em um contraponto, ressaltamos que existem muitas pessoas sem acesso a computadores e à Internet, mas não podemos ficar restritos a essa constatação. Na verdade, a exclusão que existe não é somente digital, mas é muito mais social, psicológica, de acesso a conhecimento e informação e mesmo cidadania.

Complementando, o desenvolvimento de uma educação contiuada deve ser outro objetivo e desafio da Educação para o século XXI. Isso significa que reflitamos sobre somente acumular informações sem atribuir nosso próprio significado a elas, de acordo com nossa atual capacidade de compreensão. Ou seja, que melhor compreendamos o mundo a partir da nossa experienciação. Para que ocorra este nível de aprendizagem, é fundamental aprender a aprender. Para tanto, é preciso criar situações-problema que levem o adulto tardio a fazer um esforço de melhor auto-organização, incorporando as tecnologias em suas estruturas e reorganizando-se novamente e, neste caso, nos reportamos aos adultos tardios, sendo imprescindível que esta Educação os atinja.

A educação formal e não-formal deve transmitir de forma maciça e eficaz, cada vez mais trabalhando saberes, coibindo a exclusão digital, contestando os métodos de ensino ineficazes, revendo as próprias instituições, provocando, assim, a Educação ao longo da vida. Através dessa nova aprendizagem digital, precisamos tornar o adulto tardio capaz de compreender o seu papel social e o significado dessas suas novas aprendizagens, para usá-la melhor em seu dia a dia, de forma a atender suas exigências e as da própria sociedade, promovendo sua inclusão digital e até social.

Devemos pensar em uma Educação digital para uma cidadania global, a fim de formar os seres humanos capazes de conviver e dialogar. Preparar os cidadãos para serem contemporâneos de si mesmos, menos egoístas, resgatando como um todo, visando assim humanizar as relações intergeracionais, desenvolvendo uma consciência de solidariedade e compreensão de que evoluímos individual e coletivamente, possibilitando o surgimento de pessoas capazes de sonhar, ser feliz e realizada consigo mesmas, refletindo e encontrando soluções mais adequadas e duradouras, a fim de aplacar os problemas da humanidade.

Diz Kachar (2003, p. 155) que “[...] o desafio de enfrentar o computador e dominá-lo é uma prova da própria capacidade de lidar com situações novas, 
coragem de aventurar-se no desconhecido e descobrir que pode apostar em si mesma para abrir novas portas e desconstruir os muros internos".

Os adultos tardios que adquirirem novas competências, compreenderem e acompanharem as mudanças tecnológicas e suas efetivas atuações na sociedade, estarão inseridos com mais facilidade nesse novo formato de sociedade alicerçado nas tecnologias que, segundo Lévy (1996, p. 60), é “[...] uma capacidade continuamente alimentada e melhorada de aprender e inovar, que pode se atualizar de maneira imprevisível em contextos variáveis". É nesse sentido que o adulto tardio pode e deve apropriar-se das TICs, ao saber usá-las intensificará seu processo de aprendizagem, para além da experiência de vida ele já possui, interagindo com diferentes e novas informações, pessoas e grupos, a partir de seus interesses e motivações, socializando seus conhecimentos, conforme suas próprias histórias de vida, tornado mais realista sua autoestima e autorealização.

Mas, para que isso aconteça, ele deve participar de uma Educação continuada, em que seja visto como um ser inconcluso, ao mesmo tempo que em crescimento constante, que necessita estar inserido em um contexto que privilegie a Educação, ao longo da sua vida, revelando suas facilidades/dificuldades em entender essa novas linguagens, procurando participar ativamenet de cursos, para não permanecer alienado e marginalizado, então, conseguindo reduzir seu tédio, isolamento, ativando elementos de suas atividades mentais e, sobretudo, fortalecendo seus vínculos afetivos e sociais.

Como bem salienta Mosquera (2003, p. 54),:

\begin{abstract}
[... ] a transição de um século para outro, de um milênio para outro. Se intensifica a idéia de uma nova cultura, uma nova sociedade e um novo sujeito para a Educação. Já estamos a caminho, porém a estrada é árdua e precisamos aprender a caminhar caminhando. Este caminhar não é apenas uma tentativa, mas uma intenção de elaborar novas vias que levem a uma humanidade renovada.
\end{abstract}

Mosquera (1986, p. 357) nos coloca que “[...]a vida adulta é um enorme desafio, pois de sua compreensão e equilíbrio depende, em grande parte, a dinâmica das outras gerações". Nesse sentido, aprender sobre Informática e TICs passa a ser também uma realização pessoal, porque muitos destes adultos tardios trazem uma 'bagagem carregada de preconceitos e descréditos', impostos tanto pelas suas famílias como pelo meio em que (com) vivem. Porém, com suas novas motivações conseguem entender que ainda podem continuar aprendendo. 
Também salientamos (MOSQUERA; STOBÄUS, 2011) que é possível envelhecer de modo saudável, levando em conta intersecções entre os campos de Educação, Saúde e Psicologia Positiva, permitindo ter mais cuidado de si e desenvolver-se.

O desenvolvimento ao longo de toda a vida, lifespan approach, desenvolvido por Baltes, trata de enfatizar elementos que as pessoas utilizam para vencer possíveis fatores obstucalizadores de seu desenvolvimento, mormente adultos tardios, ressaltado por Mosquera, Stobäus, Lindôso e Tamanini (2011).

O trabalho de Goulart (2011) encontrou que a maioria dos adultos tardios possui interesses, necessidades e dificuldades, até consideradas como mais 'comuns', em relação à aprendizagem digital. Através desses elementos discutidos na pesquisa, pelas suas respostas, tanto nas aulas, como em suas performances, pudemos observar que os seus maiores interesses e necessidades foram em tentar continuar participando da sociedade e o tentar poder romper algumas das 'barreiras' que encontram no caminho, sendo, talvez, o maior desafio o continuar protagonistas de suas próprias vidas, sem precisar de (tanto) auxílio, ou de ficar realmente na dependência de terceiros, para não 'incomodar e acomodar-se'.

Salientamos a importância de saber mais sobre Informática e TICs e o tentar realizar tarefas sozinho, como navegar na Internet, o que tem a conotação de poder ir além das fronteiras até então propostas, conseguir sair do seu lugar comum e tentar conhecer e participar de um mundo global, incluindo-se, assim, em uma sociedade maior.

Ainda segundo Goulart (2011), houve aspectos ressaltados como dificuldades, e existem muitas mais a serem vencidas, algumas desmistificadas ao longo das atividades desenvolvidas. Outra dificuldade refere-se a aspectos de memória, podendo ser superada por atividades que impliquem realização de repetições e relações com aspectos mais do cotidiano (aprendizagens prévias). Porém, são proveitosas, por exemplo, ao longo de curso/oficina, sendo bem orientados a fazerem a repetição de tarefas diferenciadas, em ritmo mais personalizado, com monitoria constante e paciente, da realização de atividades, quando podem, em casa e com auxílio por exemplo de familiares.

Outras dificuldades encontradas foram: ícones muito pequenos; apresentar alguma falta de coordenação motora (fina) para utilizar adequadamente o mouse; pressionar o teclado com muita força; tentativa de utilização simultanea de 'janelas abertas'.

Novamente salientamos que a parcimoniosa monitoria pode ensinar essas pessoas a como configurar os ícones para ficar do tamanho desejado; a como manusear o mouse de forma mais produtiva; a como voltar à janela que queriam. 
Os adultos tardios que fizeram o curso sabem bem que um único curso não vai atender todas suas demandas, que necessitam aprender a lidar com o computador e a navegar na Internet mais vezes, que precisam procurar mais informações para saberem quendo e onde acontecem outros cursos com o mesmo enfoque.

Observou Goulart (2011) que muitos idosos que chegam para fazer o curso têm uma visão, talvez não tão positiva, em relação a si mesmos, de certa forma relacionada às suas experiências anteriores, possivelmente com menos elementos saudáveis de conhecimento de níveis reais e saudáveis de autoconceito e de autoimagem e autoestima, bem como relações interpessoais mais salutares.

Entendemos ser possível que cursos/oficinas de Inclusão Digital, voltados para esse público, realizados com esse tipo de estratégia sem erros, de forma criativa e mais atrativa, pode proporcionar possibilidades para que esses adultos tardios construam seus próprios aprendizados de forma significativa, desenvolvendo mais iniciativa, autonomia e aprendendo de forma mais construtiva.

Podemos ressaltar que, através dos resultados e proposições desta pesquisa, Goulart (2011) confirmou que mais do que quaisquer outras pessoas, deve-se ter a preocupação de investir mais forte em possibilidades de Educação desses adultos tardios, quer dentro das diversas oportunidades em instituições de Ensino Superior, que foi o caso presente, quer em cursos formais ou informais, por exemplo, em ONGs, com as mais variadas tecnologias e com possibilidades de produzir aprendizagens significativas, com valores éticos e concretos para que, em suas vidas, possam agir de forma mais positiva, dentro de climas alegres e descontraídos de convivência e de valorização da pessoa, cada qual com sua história, sabedoria e modo peculiar de aprender e desenvolver-se continuamente.

Por outro lado, em termos de ensino, estaria o propósito de conseguir motivar os adultos tardios para que continuem aprendendo, mesmo diante de suas limitações e dificuldades, repassando-a para suas famílias, amigos e para a sociedade. Lembremos que uma forma sadia e positiva pode ser conseguida, levando em conta a afetividade nas relações docente-discente, conforme Fontoura, Stobäus e Mosquera (2011).

\section{Considerações Finais}

Ao longo do texto, tentamos responder sobre o que motiva adultos tardios a procurarem cursos de inclusão digital e realizarem aprendizagens 
significativas. Conseguimos ponderar, pelas leituras e relatos de pesquisa, que essa motivação é algo muito presente na vida de pessoas que procuram cursos para aprenderem Informática e, dessa maneira, incluir-se digitalmente. $\mathrm{O}$ mesmo aconteceu na pesquisa relatada. Constata-se que são vários os motivos para aprender, entre eles destacamos: o desejo de aprender mais ou continuar aprendendo para não ser excluído, tanto da sociedade como do núcleo familiar, ao não falar e entender a linguagem das tecnologias; tentar superar dificuldades e dominar o uso do computador, como enviar e-mails ou navegar na Internet; melhorar nas relações interpessoais familiares, intergeracionais e realizar-se pessoalmente; e tentar tornar sua autoimagem e autoestima mais realista/positiva.

Mesmo com tantas perdas físicas, psicológicas e sociais, muitos adultos tardios estão altamente motivados a incorporar essas TICs em suas vidas, através de cursos de Informática. Contudo, constatamos também, que para aqueles que fizeram o curso, o desafio estava, portanto, na incorporação dessas tecnologias a seus processos de aprendizagem, o que oportuniza a participação ativa em diversas atividades, que exigem investimentos intelectuais, mas também emocionais e mesmo físicos, tentando não simplesmente desenvolver habilidades, mas realmente atitudes proativas, em que cada qual, de sua forma e em seu ritmo, em um processo contínuo, consegue aprender sem (muitos) erros, salientando a si mesmo que tem condições de aprender ao longo da vida, possibilitando melhora em sua qualidade de vida, posteriormente atingindo também sua família e amigos, e possivelmente a sociedade como um todo.

Encerrando, cabe ressaltar de que não podemos mais permanecer 'neutros' ante a questão da possibilidade de inclusão digital, uma vez que, em um mundo tão desafiador e cada vez mais competitivo e individualizador, temos mesmo a obrigação de cuidar e motivar nossos adultos tardios, até porque todos chegaremos a esse estágio de vida daqui a (bem) pouco tempo, para que suas (nossas próprias) aprendizagens sejam sempre florescentes e continuem dando frutos ao longo da vida, de forma a mais positiva possível.

\section{DIGITAL INCLUSION IN LATE ADULTHOOD AND LEARNING REDELIGHT}

abstract

This article includes a brief history of the society of information and communication technologies, the life stage denominated late adult- 
hood and life-long learning. There are several motivations in the life

of late adults for seeking courses to learn computing as: the desire to learn more or keep learning not to be deleted, both in society and in his/her family, because of not speaking and understanding the language in the use of the technologies; overcome the difficulties and dominate the use of the computer; improve the intergenerational relationship and hold themselves personally increasing their self-esteem.

keywords

Late Adulthood. Digital Inclusion. Information and Communication Technologies. Learning.

referências

ARAÚJO, Vânia. M. R. H. Miséria informacional: o paradoxo da subinformação e superinformação. Inteligência Empresarial, Rio de Janeiro, n. 7, abr. 2001.

ASSMANN, Hugo. Reencantar a educação: rumo à sociedade aprendente. Petrópolis: Vozes, 1998.

ASSMANN, Hugo. Redes digitais e metamorfose do aprender. Petrópolis: Vozes, 2005.

BORGES, Maria Alice Guimarães. A compreensão da sociedade da informação. Ciência da Informação. Brasilia, v. 29, n. 3, p. 25-32, set/dez. 2000. Disponível em: <http:// www.scielo.br/scielo. php?script=sci_arttext\&pid=S0100-19652000000300003 >. Acesso em: 30 mai. 2011

CLAXTON, Guy. O desafio de aprender ao longo da vida. Porto Alegre: Artmed, 2005.

EIZIRIK, Marisa F. É preciso inventar a inclusão. In: PELLANDA, Nize. M. C. et al. Inclusão digital: tecendo redes afetivas/cognitivas. Rio de Janeiro: DP\&A, 2005.

FERREIRA, Anderson J. Inclusão Digital de Idosos: desenvolvendo potencialidades. In: FERREIRA, Anderson J. et al. (Orgs.). Inclusão digital de idosos: a descoberta de um novo mundo. Porto Alegre: EDIPUCRS, 2008. p. 39-48.

FONTOURA, Camila. F., STOBÄUS, Claus. D.; MOSQUERA, Juan. J. M. O docente como modelo de relações afetivas motivadoras para aprendizagens positivas. La Salle. Canoas, v. 16, N. 1, p. 73-88, 2011

GOULART, Denise. Aprendizagem sem erro em idosos nas oficinas de inclusão digital 2011. 101fl. Tese (Doutorado em Gerontologia Biomédica) - Instituto de Geriatria e Gerontologia da Pontifícia Universidade Católica do Rio Grande do Sul, 2011.

KACHAR, Vitória. Terceira Idade e informática: aprender revelando potencialidades. São Paulo: Cortez, 2003.

LÉVY, Pierre. O que é o virtual? São Paulo: Editora 34, 1996.

LÉVY, Pierre. Cibercultura. 4. ed. São Paulo: Editora 34, 2003.

MORIN, Edgar. Os sete saberes necessários à educação do futuro. São Paulo: Cortez, 2001. 
MOSQUERA, Juan J. M. Análise crítica da educação de adultos através de características psicossociais do seu desenvolvimento. Educação, Porto Alegre, ano 8, n. 9, p. 17-32, 1985.

MOSQUERA, Juan J. M. Adulto, desenvolvimento físico e educação. Veritas, Porto Alegre, v. 31, n. 123, p. 357-363, 1986.

MOSQUERA, Juan J. M. Pessoa ldosa; problema ou esperança? Veritas, Porto Alegre, V. 38, n. 149, p. 113- 131, 1993.

MOSQUERA, Juan J. M. A Educação no Terceiro Milênio. Educação. Porto Alegre, ano 8, p. 43-58, 2003.

MOSQUERA, Juan J. M.; STOBÄUS, Claus D. O envelhecimento saudável: Educação, Saúde e Psicologia Positiva. II Congresso Luso-Brasileiro de Psicologia da Saúde, Anais... São Bernardo do Campo, Universidade Metodista de São Paulo, p. 1-11, 2011.

MOSQUERA, Juan J. M., FERREIRA, Anderson J.; STOBÄUS, Claus D. Oficinas de inclusão digital para idosos: aprendizado de novos conceitos de envelhecimento. Conferência IAD/S Ibero-americana mww/Internet 2009, Madrid - Alcalá de Henares. p. 373-377, 2009.

MOSQUERA, Juan J. M.; STOBÄUS, Claus D.; LINDÔSO, Zayana.; TAMANINI, Sionara. Perspectiva Life-span na Psicologia do Envelhecimento: um olhar diferenciado sobre perdas na velhice. In: SCHWANKE, Carla H. A.; GOMES, Irênio; LINDÔSO, Zayana. C. L.; DE CARLI, Geraldo A. Atualizações em Geriatria e Gerontologia N: o processo saúdedoença no envelhecimento. Porto Alegre: Edipucrs, 2011, v. 1, p. 1-15.

OSÓRIO, Agustin R. Educação Permanente e Educação de Adultos. Porto: Piaget, 2003.

PAPALIA, Diane E.; OLDS, Sally W. Desenvolvimento Humano, 7. ed. Porto Alegre: Artes Médicas Sul, 2000

PEIXOTO, Clarice E.; CLAVAIROLLE, Françoise. Envelhecimento, politicas sociais e novas tecnologias. Rio de Janeiro: FGV, 2005.

STOBÄUS, Claus D.; MOSQUERA, Juan J. M. A neuropsicopedagogia e seus aportes para o auto-conhecimento e o trabalho. II Congresso Brasileiro de Psicologia da Saúde. Anais... Uberlândia-MG, Universidade Federal de Uberlândia, 2010. p. 1- 15.

STOBÄUS, Claus D.; GIRAFFA, Lucia M. M. Análise crítica da utilização do computador na escola. Educação, Porto Alegre, ano 17, n. 26, p.143-151, 1994.

VANZO, Elvizio T. Você@digital: esteja pronto para a revolução da informação. São Paulo: Editora Infinito, 2000.

WYGTSKY, Lev S. Pensamento e Linguagem. São Paulo: Martins Fontes, 1993.

XIBERRAS, Martine. As teorias da exclusão: para uma construção do imaginário do desvio. Lisboa: Instituto Piaget, 1993.

Recebido: 24/06/2011

1ª Revisão: 29/06/2012

2a Revisão: 19/07/2012

Aceite Final: 30/01/2013 